\title{
EVALUASI TEBAL PERKERASAN JALAN RAYA SECANG-MAGELANG MENGGUNAKAN METODE ANALISA KOMPONEN
}

\author{
Sudarno ${ }^{1}$, Akhmad Nurul Falakh², Nazila Dewi Navitasari ${ }^{3}$ \\ Teknik Sipil, Fakultas Teknik, Universitas Tidar \\ Jl. Kapten Suparman No.39 Potrobangsan, Magelang 56116 \\ sudarnosmart@gmail.com
}

\begin{abstract}
Road is one of the land transportation infrastructure that has an important role for economic growth, social-culture, tourism development, and defense of security to support national development. In this study the thickness analysis of pavement using Bina Marga method 1987 with the age of 10 years to come. This overlay planning calculation uses Laston MS 340 where the average field CBR data using Dynamic Cone Penetrometer (DCP) with a conical size of 600 is 35.2. Then from the data obtained the value of Land Supporting Capacity (DDT) of 8.4 and the average 5-year Average Lifecycle (LER) value of 550.4 and for the second five years 1195.57. From the overall calculation, it is known that the surface layer thickness is $7.5 \mathrm{~cm}$, so the road does not require overlay.
\end{abstract}

Keyword: Pavement, Evaluation

\begin{abstract}
ABSTRAK
Jalan merupakan salah satu prasarana perhubungan darat yang mempunyai peranan penting bagi pertumbuhan perekonomian, sosial-budaya, pengembangan wilayah pariwisata, dan pertahanan keamanan untuk menunjang pembangunan nasional. Pada penelitian ini analisis tebal lapis perkerasan jalan menggunakan metode Bina Marga 1987 dengan umur rencana 10 tahun yang akan datang. Perhitungan perencanaan overlay ini menggunakan Laston MS 340 dimana data CBR lapangan rata-rata menggunakan Dynamic Cone Penetrometre (DCP) dengan ukuran konus $60^{\circ}$ sebesar 35,2. Kemudian dari data tersebut diperoleh nilai Daya Dukung Tanah (DDT) sebesar 8,4 dan nilai Lintas Ekuivalen Rata-Rata (LER) lima tahun pertama 550,4 dan untuk lima tahun kedua 1195,57. Dari hasil perhitungan keseluruhan diketahui bahwa tebal lapis permukaan sebesar $7,5 \mathrm{~cm}$, sehingga jalan tersebut belum memerlukan pelapisan ulang (overlay).
\end{abstract}

Kata kunci: Lapis Perkerasan, Evaluasi.

\section{Pendahuluan}

Jalan merupakan prasarana transportasi perhubungan darat yang mempunyai peranan penting bagi pertumbuhan perekonomian, sosial budaya, pengembangan wilayah pariwisata, dan pertahanan keamanan serta persatuan bangsa ( Fitriana, 2014)

Jumlah moda transportasi di Kota Magelang saat ini meningkat secara signifikan sehingga mengakibatkan kepadatan pada ruas jalan dan menimbulkan beban berlebih pada kapasitas layan jalan tersebut (Utama, 2016).

Meningkatnya jumlah kendaraan yang lewat di atas permukaan jalan menyebabkan turunnya tingkat pelayanan jalan berupa kerusakan ( setiowati, 2011).Salah satu cara untuk mengatasi agar tebal perkerasan tidak mudah mengalami kerusakan, maka perlu diadakan studi kasus untuk mendapatkan tebal perkerasan yang terbaik (Pradani \& Fithriayuni, 2016). Dalam penelitian ini menggunakan Metode Bina Marga 1987. Faktor utama yang mempengaruhi tebal lapis perkerasan tersebut adalah beban lalulntas harian rata-rata (LHR)( Zainul dkk, 2007).
Perencanaan perkerasan lentur adalah memilih dan menetapkan kekuatan konstruksi perkerasan yang sesuai dengan kondisi (Yuliatai dan Fitria, 2012). Penggunaan perkerasan lentur lebih murah dibandingkan perkerasan kaku (Andriansyah dkk, 2016) Perhitungan tebal perkerasan lentur jalan raya dapat dipengaruhi oleh faktor-faktor lokal seperti: peranan dan fungsi jalan, volume lalulintas, daya dukung tanah dan iklim .

Di Indonesia, dalam menentukan daya dukung tanah dasar untuk perencanaan tebal perkerasan jalan digunakan uji California Bearing Ratio (CBR) lapangan (Oetomo dan Wateno, 2013).

Pengujian Dynamic Cone Penetrometer (DCP) untuk menentukan nilai CBR (California Bearing Ratio) tanah dasar, timbunan, dan atau suatu sistem perkerasan (Lengkong dan Prisila, 2013). Biasanya pembacaan akan diambil pada sejumlah pukulan tetap, yaitu, 1 pukulan untuk material lunak, 5 pukulan untuk material "normal" dan 10 pukulan untuk yang sangat sangat resistif (Azwarman, 2015). 
Nilai DCP yang diambil adalah jumlah rata-rata dari penetrasi per pukulan ( $\mathrm{mm} / \mathrm{blow}$ ) (Sriharyani dan Oktami , 2016). Indeks tebal perkerasan merupakan sebuah nilai yang berperan (berfungsi) untuk menentukan tebal dari masing-masing lapis perkerasan (Akbar dkk, 2014)

\section{Metodologi Penelitian}

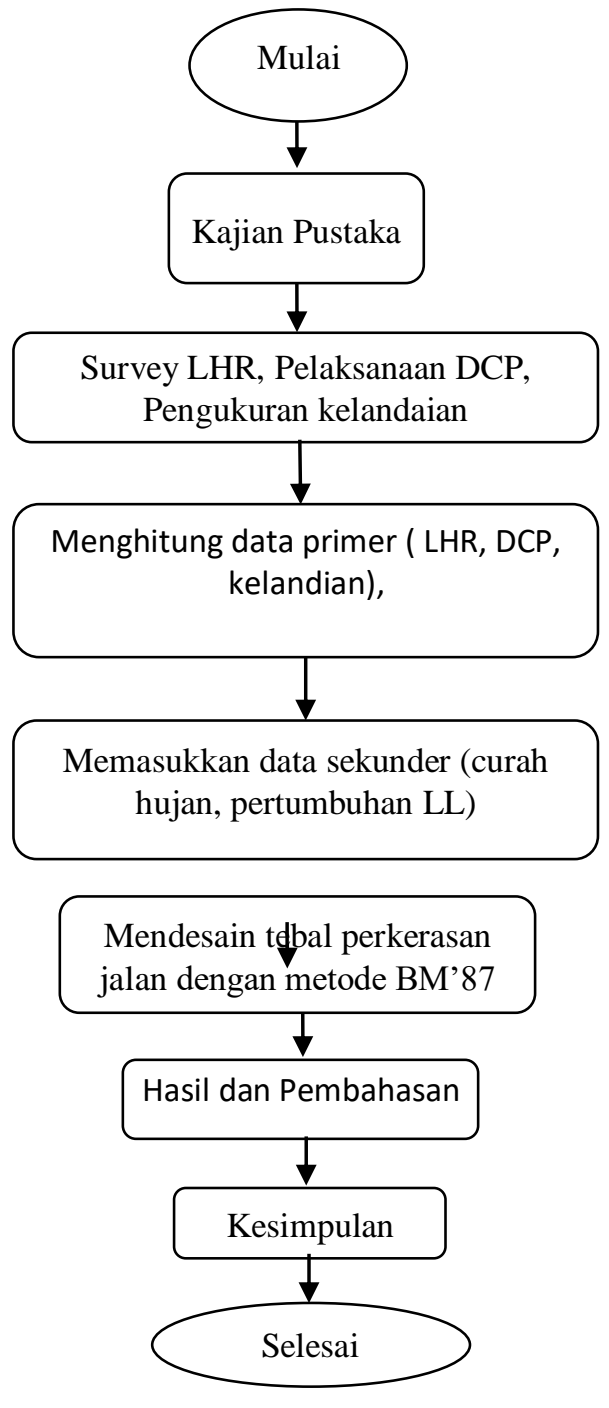

Gambar 1. Diagram Alur Penelitian

\section{Hasil Dan Pembahasan}

Hasil

Data Primer, diambil langsung di lapangan sebagai berikut :

Data Kendaraan

Pengamatan dilakukan padahari Kamis, 24 November 2017 pukul $06.30 \mathrm{~s} / \mathrm{d}$ 09.30 WIB dan pukul $16.00 \mathrm{~s} / \mathrm{d} 18.00$ WIB. Pengamatan dilakukan pada waktu jam puncak.
Tabel 1. Hasil Survey Kendaraan Bermotor

\begin{tabular}{lcc}
\hline Jenis Kendaraan & $\begin{array}{l}\text { Jumlah } \\
\text { per 4 } \\
\text { jam }\end{array}$ & $\begin{array}{l}\text { Jumlah } \\
\text { Per 24 } \\
\text { jam }\end{array}$ \\
\hline Mobil Pribadi & 1325 & 7950 \\
\hline $\begin{array}{l}\text { Mini Bus dan } \\
\text { Truk Kecil }\end{array}$ & 366 & 2196 \\
\hline $\begin{array}{l}\text { Bis Besar, Truk 2 } \\
\text { As }\end{array}$ & 459 & 2754 \\
\hline Truk 2 As 13 Ton & 24 & 144 \\
\hline Truk 3 As, Trailer & 69 & 414 \\
\hline
\end{tabular}

Tabel 2. Hasil Pengukuran CBR di Lapangan

\begin{tabular}{ccc}
\hline $\begin{array}{c}\text { Titik } \\
\text { ke }\end{array}$ & $\begin{array}{c}\text { Penetrasi DCP } \\
\text { rata-rata }(\mathrm{mm})\end{array}$ & $\begin{array}{c}\text { CBR menurut } \\
\text { Grafik }\end{array}$ \\
\hline 1 & 4,967 & 80 \\
\hline 2 & 5,867 & 68 \\
\hline 3 & 5,167 & 72 \\
\hline 4 & 6,1 & 60 \\
\hline 5 & 9,267 & 35 \\
\hline 6 & 5,6 & 70 \\
\hline 7 & 7,533 & 43 \\
\hline 8 & 15,55 & 19 \\
\hline 9 & 7,467 & 47 \\
\hline 10 & 7,033 & 50 \\
\hline & Rata-Rata & 54,4 \\
\hline
\end{tabular}

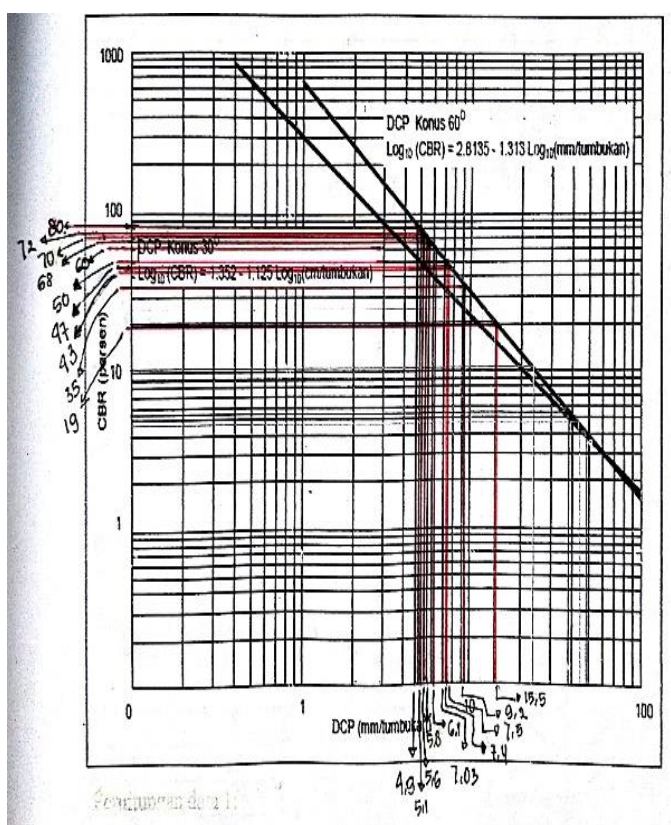

Gambar 2. Hubungan Penetrasi dan CBR

Untuk menentukn nilai CBR berdasarkan penetrasi DCPkonus 60 menggunakan Rumus (Zainul dkk, 2007) : 
$\log _{10}(C B R)=2,8135-1,313 \log _{10}\left(\frac{\mathrm{mm}}{\text { tum }}\right)$

$R=3,18$,berdasarkan 10 titik pengamatan CBR [4]

$C B R$ Segmen $=\overline{C B R}-\left[\frac{C B R \text { maks }-C B R \text { min }}{R}\right]$

$C B R$ Segmen $=54,4-\left[\frac{80-19}{3,18}\right]=35,217$

$D D T=1,6649+4,3592 \log C B$ Rsegmen

$D D T=1,6649+4,3592 \log (35,217)=8,4$

Berdasarkan data CBR yang telah ada kemudian menghitung DDT (Daya Dukung Tanah) CBR Maks = 80, CBR Min = 19 Menghitung Kelandaian jalan menggunakan Theodolit Digital dihasilkan kelandaian $1,086 \%$.

Data sekunder Pertumbuhan Lalu Lintas Diambilkan dari data BPS, jumlah kendaraan pada tahun 2010-2015 mencapai $3 \%$ (pertumbuhan 3\%).

Curah hujan di Kabupaten Magelang sebagian besar tergolong beriklim basah dengan curah hujan tahunan berkisar dari 2300-3000 mm.

Klasifikasi Jalan Raya Secang-Magelang termasuk kategori Jalan Kolektor.

\section{Pembahasan}

Umur Rencana 5 tahun pertama 2022 dan 5 tahun kedua $2027=10$ tahun

Pertumbuhan Lalu Lintas 3\%

Tabel 3. Lalu lintas harian rata-rata

\begin{tabular}{llll}
\hline $\begin{array}{l}\text { Jenis } \\
\text { Kendaraan }\end{array}$ & $\begin{array}{l}\text { LHR } \\
\text { pada } \\
\mathbf{2 0 1 7}\end{array}$ & $\begin{array}{l}\text { LHR } \\
\text { pada } \\
\mathbf{2 0 2 2}\end{array}$ & $\begin{array}{l}\text { LHR } \\
\text { pada } \\
\mathbf{2 0 2 7}\end{array}$ \\
\hline $\begin{array}{l}\text { Mobil } \\
\text { Penumpang }\end{array}$ & 7950 & 9217 & 10685 \\
\hline $\begin{array}{l}\text { Mini Bus \& } \\
\text { Bus kecil }\end{array}$ & 2196 & 2546 & 2952 \\
\hline $\begin{array}{l}\text { Bis Besar 2 } \\
\text { As }\end{array}$ & 2754 & 3193 & 3702 \\
\hline $\begin{array}{l}\text { Truk 2 As 13 } \\
\text { Ton }\end{array}$ & 144 & 167 & 194 \\
\hline $\begin{array}{l}\text { Truk 3 As \& } \\
\text { Trailer }\end{array}$ & 414 & 480 & 557 \\
\hline Jumlah & $\mathbf{1 3 4 5 8}$ & $\mathbf{1 5 6 0 3}$ & $\mathbf{1 8 0 9 0}$ \\
\hline \multicolumn{4}{l}{ LHR pada 2022= LHR 2017x(1+i } \\
LHR pada 2027= LHR 2022x $(1+\mathrm{i})^{5}$
\end{tabular}

Tabel 4. Angka ekivalen

\begin{tabular}{lllll}
\hline $\begin{array}{l}\text { Jenis } \\
\text { Kenda }\end{array}$ & $\begin{array}{l}\text { Angka } \\
\text { Ekuiva }\end{array}$ & LEP & LEA & LEA \\
raan & $\begin{array}{l}\text { len } \\
(E)^{*}\end{array}$ & & & 2022 \\
& & & \\
\hline $\begin{array}{l}\text { Mobil } \\
\text { Penu } \\
\text { mpang }\end{array}$ & 0,0004 & 1,59 & 1,84 & 2,14 \\
\hline Mini & 0,0004 & 174,91 & 202,79 & 235,1 \\
Bus \& & & & & \\
Bus & & & & \\
Kecil & & & & \\
\hline Bis & 0,1593 & 481,95 & 558,77 & 647,85 \\
Besar & & & & \\
2 As & & & & \\
\hline Truk 2 & 1,0648 & 76,66 & 88,91 & 103,28 \\
As 13 & & & & \\
Ton & & & & \\
\hline Truk 3 & 1,3753 & 284,68 & 330,07 & 383,02 \\
As \& & & & & \\
Trailer & & & & \\
\hline & Jml & 1019,7 & 1182,3 & 1371,3 \\
& & 5 & 8 & 9 \\
\hline
\end{tabular}

LET $=0,5 \times($ LEP + LEA2022 $)=0,5 \times(1019,75+1182,38)$ $=1100,815$

$\mathrm{LER}=\mathrm{LETxUR} / 10$

LER 5 Th Pertama $=1100,815 \times 5 / 10=550,4$

LER 5 Th Kedua $=(0,5(1019,75+1371,39)) \times 10 / 10$ $=1195,57$

Curah Hujan $=2300-3000 \mathrm{~mm} / \mathrm{th}$

Prosentase Kendaraan Berat terhadap kendaraan ringan $=((2754+144+414) / 13458) \times 100 \%=24,6 \%$

Kelandaian 1,086\%

Faktor Regional diperoleh sebesar 1,5

IPt dengan LER pada 5 tahun pertama $(550,4)$ dengan klasifikasi jalan Kolektoryaitu 2,0. Sedangkan pada 10 tahun kemudian LER $(1195,57)$ dengan klasifikasi jalan Kolektor memperoleh $\mathrm{IPt}=2,0$.

Analisis ini menggunakan Laston dengan $\mathrm{MS}=$ 340 (kg), karena tanah yang diteliti adalah tanah timbunan. Kemudian, untuk batu pecah yang digunakan adalah batu pecah kelas $\mathrm{C}$.

Berdasarkangambar pada nomogram 4 korelasi CBR dan DDT dibawah ini:

Maka CBR 35,2 ditarik garis ke kiri ditemukan DDT 8,4. 


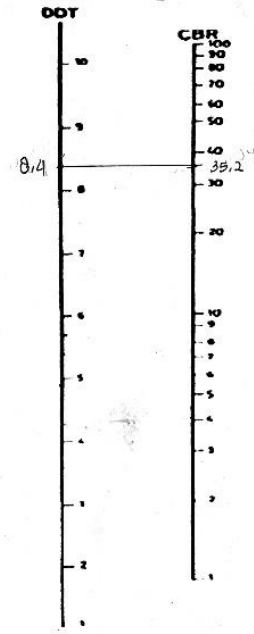

Gambar 3. Hubungan CBR dan DDT

Pada 5 Tahun Pertama

Kemudian dengan menggunakan nomogram 4 dibawah ini:

Ditarik garis dari DDT ke LER terus ke ITP dan ITP akan ditemukan angka:

ITP untuk 5 tahun pertama (2022) $=5,6$

ITP untuk 5 tahun kedua $(2027)=6,3$

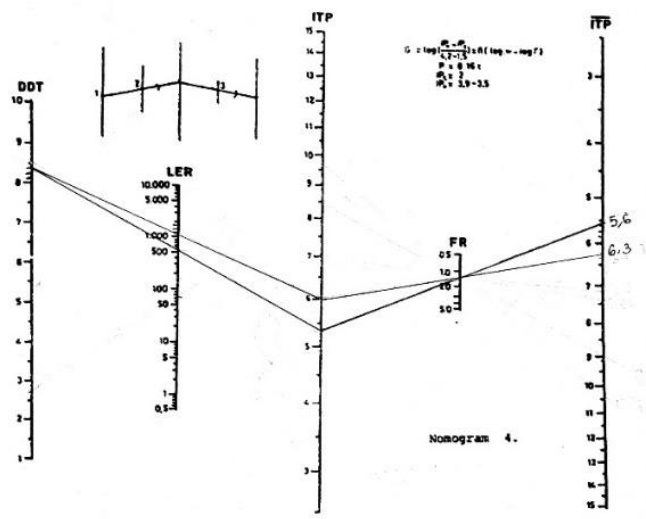

Gambar 4. Nomogram 4 Bina marga' 87

Untuk tebal lapis 5 tahun pertama (2022)

Tebal lapis minimum dilihat dari ITP=5,6

Lapisan permukaan: Laston, MS 340; d1 =7,5

Lapisan pondasi atas: Batu pecah kelas $\mathrm{C} ; \mathrm{d} 2$ $=20$

Lapisan pondasi bawah: Sirtu kelas C; $\mathrm{d} 3=10$

$$
\begin{gathered}
\overline{I T P}=(a 1 x d 1)+(a 2 x d 2)+(a 3 x d 3) \\
\overline{I T P}=(0,3 \times 7,5)+(0,12 \times 20)+(0,11 \times 10) \\
5,6=(0,3 x 7,5)+(0,12 x 20)+(0,11 x d 3) \\
d 3=\frac{5,6-4,65}{0,11}=8,63 \mathrm{~cm}=9 \mathrm{~cm}
\end{gathered}
$$

Untuk tebal lapis 5 tahun Kedua (2027)

Koefisien kekuatan relatif, dilihat dari tabel koefisien reltif

Lapisan permukaan: Laston, MS 340; a1 $=0,30$
Lapisan Pondasi atas: Batu pecah kelas C; a2 $=0,12$

Lapisan pondasi bawah: Sirtu Kelas C; a3= 0,11

Tebal Lapis minimum dilihat dari ITP $=6,3$

Lapisan permukaan: Laston, MS $340 \mathrm{~d} 1=7,5$

Lapisan pondasi atas: Batu Pecah kelas $\mathrm{C} d 2=$ 20

Lapisan pondasi bawah: Sirtu kelas $\mathrm{C} d 3=10$

$$
\begin{gathered}
\overline{I T P}=(a 1 x d 1)+(a 2 x d 2)+(a 3 x d 3) \\
\overline{I T P}=(0,3 x 7,5)+(0,12 \times 20)+(0,11 \times 10) \\
6,3=(0,3 x 7,5)+(0,12 x 20)+(0,11 \times d 3) \\
d 3=\frac{6,3-4,65}{0,11}=15 \mathrm{~cm} \\
6,3=(0,3 x d 1)+(0,12 \times 20)+(0,11 \times 15) \\
6,3=0,3 d 1+2,4+1,65 \\
d 1=7,5 \mathrm{~cm}
\end{gathered}
$$

Tebal lapis aspal hasil pengukuran adalah $13,2 \mathrm{~cm}$, maka d0 yang terjadi pelapisan ulang adalahDo $=13,2$

Keperluan untuk lapis ulang $13,2-7,5=5,7 \mathrm{~cm}$ (pelapisan ulang terjadi $5,7 \mathrm{~cm}$ )

\section{Simpulan}

Berdasarkan hasil survey lalu lintas harian rata rata di ruas jalan magelang secang $\mathrm{km} 2$ diperoleh nilai LER 5 tahun pertama 550.4 dan untuk LER tahun kedua 1195. Selanjutnya perhitungan perencanaan perkerasan menggunakan Laston MS 340 dengan metode binamarga 1987 didapatkan data CBR lapangan rata-rata meggunakan dynamic cone penetrometer (DCP) dengan ukuran conus $60^{\circ}$ sebesar 35,2. Data CBR tersebut diperoleh nilai daya dukung tanah (DDT) sebesar 8,4. Kemudian dari nilai DDT dan LER yang telah dihitung maka diperoleh nilai ITP dengan menggunakan nomograf 4 mendapatkan hasil akhir $\mathrm{d} 1=7,5 \mathrm{~cm}$, sehingga tidak perlu dilakukan overlay karena jalan MagelangSecang $\mathrm{km} 2$ telah dilakukan pelapisan ulang.

\section{Daftar Pustaka}

Akbar, J. Said. \& Wesli., 2014. Studi Korelasi Daya Dukung Tanah dengan Indek Tebal Perkerasan Jalan Menggunakan Metode Bina Marga. Jurnal Teras, Volume 4, p. 62.

Andriansyah; Pratomo, Priyo; Ali, Hadi., 2016. Optimalisasi Tebal Perkerasan pada Pekerjaan Pelebaran Jalan dengan Metode MDPJ 02/M/BM/2013 dan Pt T01-2002-B. JRSDD, Volume 4, p.114.

Azwarman., 2015. Kajian Nilai Daya Dukung Tanah Dasar Menggunakan Dynamic Cone Penetrometer dan CBR In Place. Jurnal IImiah Universitas Batanghari Jambi, Volume 15, p. 151.

Departemen Pekerjaan Umum. Rancangan 3. Cara Uji CBR dengan Dynamic Cone 
Penetrometer.

https://www.academia.edu/6482454/RAN

CANGAN_3_PEDOMAN_Cara_uji_CBR dengan Dynamic Cone Penetrometer $\bar{D}$ CP DEPARTEMEN PEKERJAAN UMU $M \_$Daftar_isi. Diakses pada 09 Januari 2018 pukul 14.25 .

Fitriana, R., 2014. Studi Komparasi Perencanaan Tebal Perekerasan Kaku Jalan Tol Mneggunakan Metode Bina Marga 2002 dan Aastho 1993. Surakarta: Universitas Muhammadiyah Surakarta.

Lengkong, I. L. Prisila., 2013. Hubungan Nilai CBR Laboratorium dan DCP pada Tanah yang Didapatkan pada Ruas Halan Worilikupang Kabupaten Minahasa Utara. Jurnal Sipil Statik, Volume 1, p.369.

Oetomo, Wateno., 2013. Alternatif Lain Analisis Struktur Jalan Perkerasan Lentur pada Pembangunan Lingkar Selatan Kota Pasuruan. Jurnal Teknik Sipil Untag Surabaya, Volume 06, p. 120.

Pradani, N. \&Fithriayuni , D., 2016. Analisis Perancangan Tebal Perkerasan Lentur Menggunakan PD T-1-2002-B Metode Manual Desain Perkerasan (MDP) dan Meode Nottingham pada Jalan I Gusti Ngurah Rai Palu. Jurnal Fropil, Volume 4, p. 141.

Setyowati, S., 2011. Penilaian Kondisi Perkerasan dengan Metode Pavement Condition Index (PCI) Peningkatan Jalan dan Perhitungan Rancangan Anggaran
Biaya pada Ruas Jalan Solo-Karanganyar KM 4+400+11+050. Surakarta: Universitas Sebelas Maret.

Sriharyani, L. \& Oktami D., 2016. Kajian Penggunaan Dynamic Cone Penetrometer (DCP) Untuk Uji Lapangan pada Tanah Dasar Pekerjaan Timbunan Apron (Studi Kasus di Bandar Udara Raden Inten II Lampung). Jurnal Tapak, Volume 5, p. 92.

Utama, A. K. W., 2016. Analisis Perkerasan Jalan dengan Metode Analisa Komponen Ruas Jalan Magelang KM 10-12. Yogyakarta: Universitas Atma Jaya Yogyakarta.

Yuliatai, Fitria., 2012. Evaluasi Parameter Koefisien Distribusi Kendaraan (C) untuk Jalan Tipe 4/2UD untuk Perhitungan Tebal Perkerasan Lentur Cara Bina Marga (Studi Kasus: Jl. YoyakrtaMagelang Km 21-22 dan Jl. Jendral Ahmad Yani Magelang. Surabaya: Institut Teknologi Sepuluh Nopember.

Zainul, M, Arifin; Gagoek S P; Ramadhani Dwi., 2007. Analisa Efektifitas Fasilitas Zebra Cross pada JI. MT Haryono dan JI. Gajayana. Jurnal Rekayasa Sipil, Volume 1, p. 14.

\section{UCAPAN TERIMAKASIH}

Jurusan Teknik Sipil, Fakultas Teknik, Universitas Tidar 